\section{Commentary: Have we finally settled the debate of unilateral versus bilateral antegrade cerebral perfusion for brain protection during type A repair?}

\author{
Francois Dagenais, MD
}

In the current issue of the Journal, Norton and colleagues ${ }^{1}$ bring a significant contribution to the field of brain protection during type A aortic aneurysm repair. Norton and colleagues ${ }^{1}$ compared the outcomes of 307 patients with type A aortic dissection operated on between 2001 to 2017 with antegrade cerebral perfusion (ACP), either unilateral ACP (uni-ACP; $\mathrm{n}=140$ ) or bilateral ACP (bi-ACP; $\mathrm{n}=167)$. They report outstanding results for both ACP modes, with comparable mortalities (uni-ACP, $5.7 \%$ vs bi-ACP, 9.6\%; $P=.21$ ) and stroke rates (uni-ACP, $6.4 \%$ vs bi-ACP, $9.0 \%$; $P$ not significant). Only 3 patients $(2 \%)$ had conversion from a uni-ACP to a bi-ACP strategy for either a drop in cerebral saturation or minimal back bleeding from the left common carotid artery. Norton and colleagues ${ }^{1}$ conclude that uni-ACP is as effective as bi$\mathrm{ACP}$ for brain protection during hemiarch to zone $3 \mathrm{arch}$ replacement procedures during type A aortic dissection repair and should be the preferred method of cerebral protection both for its ease of use and to decrease the manipulation of the dissected arch tissue.

The field of cerebral protection during arch replacement procedures has evolved significantly since the introduction of deep hypothermic circulatory arrest. Although some centers report excellent results with retrograde cerebral perfusion, most centers have adopted an ACP technique combined with moderate hypothermia for most arch replacement procedures. The use of uni-ACP versus bi-

\footnotetext{
From the Department of Cardiac Surgery, Institut Universitaire de Cardiology et Pneumologie de Québec, Québec, Québec, Canada.

Disclosures: Author has nothing to disclose with regard to commercial support.

Received for publication July 26, 2019; accepted for publication July 29, 2019; available ahead of print Sept 5, 2020.

Address for reprints: Francois Dagenais, MD, Institut Universitaire de Cardiology et Pneumologie de Québec, 2725 Chemin Sainte-Foy, Québec, Québec, G1V4G5 Canada (E-mail: francois.dagenais@chg.ulaval.ca).

J Thorac Cardiovasc Surg 2020;160:626-7 0022-5223/\$36.00

Crown Copyright $(2019$ Published by Elsevier Inc. on behalf of The American Association for Thoracic Surgery

https://doi.org/10.1016/j.jtcvs.2019.07.118
}
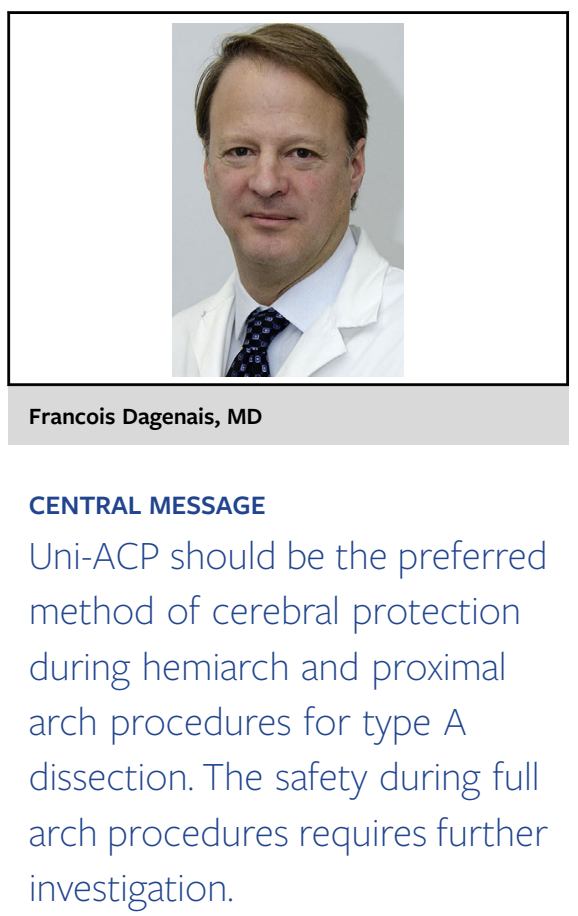

ACP has been widely debated. Norton and colleagues ${ }^{1}$ suggest similar outcomes between the strategies; however, in depth analysis of the results is needed. Although groups had similar preoperative characteristics, mean circulatory arrest times were significantly longer in the bi-ACP group (uni-ACP, 29 minutes vs bi-ACP, 45 minutes; $P<.0001$ ). Moreover, only $4(2.9 \%)$ patients in the uni-ACP group underwent a full arch replacement (zone 3 replacement), compared with $32(19 \%)$ patients in the bi-ACP group. Patients within the bi-ACP group were thus exposed to longer periods of circulatory arrest at least in part as a result of more extensive arch procedures, questioning the validity of the study conclusions for extended zone 3 arch replacement procedures.

Different techniques have been proposed to initiate ACP. The use of the axillary or innominate artery has facilitated initiation of uni-ACP. As in the study of Norton and colleagues, ${ }^{1}$ bi-ACP is classically implemented by direct ostial cannulation of the innominate and the left carotid arteries. Thereafter, with an initial uni-ACP strategy, different modifications, such as the arch-first technique with a trifurcated graft, have been developed to revascularize both cerebral hemispheres rapidly without direct arch vessel cannulation. ${ }^{2}$ In a similar rational to reperfuse both cerebral hemispheres as quickly as possible when using uni-ACP, Norton and colleagues ${ }^{1}$ propose an early revascularization of the left common carotid artery (before the left subclavian anastomosis) during total (zone 3 ) arch replacement procedures, 
thus limiting the time of "true" uni-ACP. Although such a technique ensures rapid antegrade perfusion of both brain hemispheres, in situ revascularization of the left subclavian artery may be challenging to perform routinely in all cases of type A dissection.

Although the data of the study of Norton and colleagues ${ }^{1}$ support the use of uni-ACP in hemiarch and proximal arch (zone 1 and 2) procedures in type A aortic dissection, the safety of uni-ACP during full arch procedures is inconclusive. Further studies assessing the efficacy and safety of
uni-ACP during total (zone 3) arch replacement procedures, especially during prolonged periods of circulatory arrest, are required before its use can be generalized.

\section{References}

1. Norton EL, Wu X, Kim KM, Patel HJ, Deeb GM, Yang B. Unilateral is comparable to bilateral antegrade cerebral perfusion in acute type A aortic dissection repair. $J$ Thorac Cardiovasc Surg. 2020;160:617-25.e5.

2. Bischoff MS, Brenner RM, Scheumann J, Bodian CA, Griepp RB, Lansman SL, et al. Long-term outcome after arch replacement with a trifurcated graft. J Thorac Cardiovasc Surg. 2010;140(6 Suppl):S71-6; discussion S86-91.
See Article page 617

\section{Commentary: Can unilateral antegrade cerebral perfusion constitute a unified method for acute type $A$ aortic dissection repair?}

Hitoshi Matsuda, $\mathrm{MD}, \mathrm{PhD},{ }^{\mathrm{a}}$ and Soichiro Kitamura, $\mathrm{MD}, \mathrm{PhD}^{\mathrm{b}}$

Accumulated surgical experience and resultant improvements in surgical skills, extracorporeal circulation, organ protection, and devices have led to the establishment of an integrated surgical approach for acute type A aortic dissection. ${ }^{1,2}$ Technical upgrading is continually pursued, mostly toward less invasiveness with improved endovascular techniques and more simplicity of complicated procedures for secure organ protection.

Cerebral protection is the key for successful acute type A aortic dissection treatment and is therefore essential for the postoperative prognosis. In this issue of the Journal, Norton and colleagues $^{3}$ report that cerebral perfusion with

\footnotetext{
From the ${ }^{\text {a} D e p a r t m e n t ~}$ of Cardiovascular Surgery, National Cerebral and Cardiovascular Center, Suita, Japan; and ${ }^{\mathrm{b} J a p a n}$ Cardiovascular Research Foundation, Suita, Japan.

Disclosures: Authors have nothing to disclose with regard to commercial support.

Received for publication July 25, 2019; accepted for publication July 29, 2019; available ahead of print Sept 5, 2020.

Address for reprints: Hitoshi Matsuda, MD, PhD, National Cerebral and Cardiovascular Center, 6-1 Kishibeshinmachi, Suita, Osaka, 564-8565, Japan (E-mail: hitmat_0706@ncvc.go.jp).

J Thorac Cardiovasc Surg 2020;160:627-8

$0022-5223 / \$ 36.00$

Copyright (c) 2019 by The American Association for Thoracic Surgery

https://doi.org/10.1016/j.jtcvs.2019.07.114
}

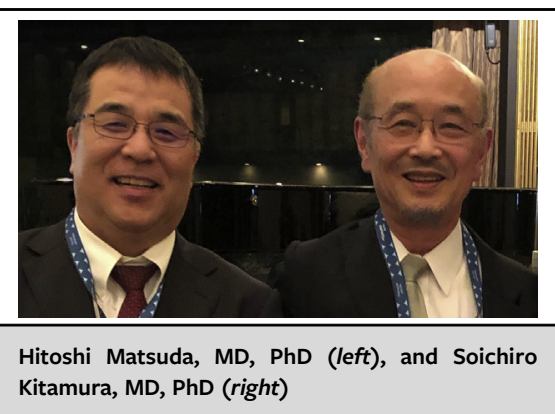

CENTRAL MESSAGE

Conversion of uni-ACP to bi-ACP was encountered in $2 \%$. It is wise to know the utility of both uniACP and bi-ACP and to then use the more effective ACP type for each patient rather than unified ACP.

antegrade cerebral perfusion (ACP) unilaterally (unilateral ACP [uni-ACP]) is comparable to bilateral ACP (bi$\mathrm{ACP}$, which has been a routine procedure.

Their comparison of medium-size cohorts reveals that 30-day mortality and postoperative stroke rate were not different and that postoperative bleeding was less and midterm survival was better for the uni-ACP group. They obtained the data from patients who were cooled to $18^{\circ} \mathrm{C}$ in the early stage and to $24^{\circ} \mathrm{C}-28^{\circ} \mathrm{C}$ in the late stage, with hypothermic circulatory arrest lasting 29 minutes for uni-ACP and 45 minutes for bi-ACP. As simple 